\title{
Pediatric Endoscopy in Calabar, an Emerging Trend - Challenges and Prospects: A Report of Two Cases.
}

\author{
O E Ngim ${ }^{1}, \mathrm{~J} \mathrm{M} \mathrm{Ikobah}^{2}$, I Ukpabio ${ }^{3}, \mathrm{G}^{\mathrm{E}}$ Bassey $^{4}$, E E Ekanem ${ }^{5}$ \\ ${ }^{I}$ Department of surgery, University of Calabar/University of Calabar Teaching Hospital,Calabar, Nigeria and \\ JIL \\ Endoscopy, 1 Edyang Street,Cross River State Housing Estate,Calabar,Nigeria. \\ ${ }^{2,4 \& 5}$ Department of Pediatrics, University of Calabar Teaching Hospital ,Calabar, Nigeria. \\ ${ }^{3}$ Department of Anesthesia, University of Calabar Teaching Hospital, Calabar, Nigeria.
}

\begin{abstract}
Data on pediatric endoscopy in Nigeria is almost non-existent. This may be due to lack of trained pediatric endoscopist or lack of facilities. Upper gastrointestinal(GI) endoscopy is thegold standard for evaluating upper GI symptoms/diseases. The majority of gastroscopies in Nigeria are done in adults but children also present with symptoms that require it,hence the need to develop pediatric endoscopy in Nigeria. This is a report of two cases done in the only private high definition video endoscopy facility in Calabar (JIL ENDOSCOPY), Nigeria. Two female children aged 10 years and 8 years had gastroscopy for swallowed foreign body (an office pin) and upper GI bleeding respectively. These patients were referred to JIL endoscopy by Pediatricians from the University of Calabar Teaching Hospital,Calabar. Conscious sedation was administered by the same anesthetist in the two cases. In the first patient, no foreign body was seen at gastroscopy while marked duodenitis was found to be responsible for the upper GI bleed in the second child. The choice of anesthesia for pediatric endoscopy has remained a topic of debate in many fora. A lot needs to be done to develop pediatric endoscopy in Nigeria.

Keywords: Pediatric endoscopy, anesthetic challenges, Calabar, Nigeria.
\end{abstract}

\section{Introduction}

Upper gastrointestinal endoscopy has been the gold standard for the diagnosis of diseases of the upper GI tract for several years now ${ }^{1-4}$. Majority of the reports on gastroscopy in the literature is among the adult populationwith reports in the pediatric age group being very scanty ${ }^{7-9}$. This has made experience in pediatric endoscopy very limited, especially in Nigeria.

Though xylocaine pharyngeal spray alonemay suffice as a form of anesthesia in adult gastroscopy, this does not apply inthe pediatric age group owing to the peculiar nature of children. The most appropriate form of general anesthesia for pediatric gastroscopy, still remains a subject of debate amongst endoscopist the world over ${ }^{10,11}$. The use of general anesthesia in addition to xylocaine pharyngeal spray for pediatric endoscopy instead of xylocaine pharyngeal spray alone as used for most adults, has additional cost implications,especially in the private setting. This is in addition to the attendant risksfaced by pediatric patients from general anesthesia. The additional cost implication, invariably makes the procedure unaffordable for some patients who rightly need the procedure. The aim of this paper is to highlight the need to develop pediatric endoscopy in Nigeria and the challenges/prospects associated with it. We also aim to create awareness amongst clinicians of the availability of this service in our environment.

\section{Materials and Methods}

This is a report of two cases referred for gastroscopy from the University of Calabar Teaching Hospital (UCTH) to JIL Endoscopy, a private endoscopy facility in Calabar, Nigeria. The same anaesthetist administered conscious sedation on these two patients using intravenous midazolam and propofol at appropriate doses. Xylocaine pharyngeal spray was also used. A high definition Olympus GIF-XQ140 Video Gastroscope was used for the procedures.

Case 1

A 10 year old female child was referred by the pediatricians to JIL Endoscopy on account of foreign body sensation in the throat. The patient had swallowed an office pin 3 days prior to presentation. She was insistent that there was a feeling of foreign body in her throat.The Endoscopy was done under conscious sedation as stated above. The gastroscopy was normal. An x-ray confirmed absence of the foreign body. 
Case 2:

An eight year old girl was referred from UCTHby the Pediatricians on account of an upper GI bleed. She also had gastroscopy under conscious sedation. The gastroscopy revealed multiple hemorrhagic lesions in the second and third parts of the duodenum (fig1) with evidence of recent bleeding. There was no ulcer in the stomach or duodenum.

No complication was recorded in the two procedures.

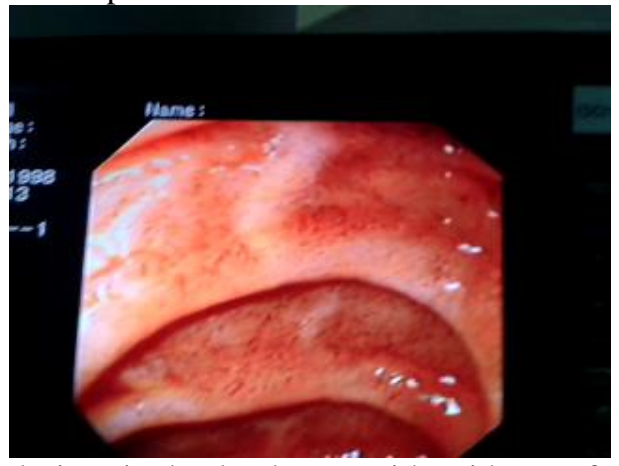

Fig1: Shows multiple hemorrhagic lesions in the duodenum with evidence of recent bleed in Case 2.

\section{Discussion}

Pediatric endoscopy is an emerging field in Nigeria and data on this subject is presently scanty. Upper gastrointestinal endoscopy still remains the gold standard for the diagnosis of diseases of the upper gastrointestinal tract (GIT) even in children ${ }^{1-4,7,8,9}$.Pediatric gastroscopy like in adults, offers both diagnostic and therapeutic benefits though special instrumentation and training may be required in children ${ }^{1-4,12}$. Generally, equipment necessary for diagnostic and therapeutic endoscopy in children older than 1-3 years of age and weighting more than 10 to $15 \mathrm{~kg}$ are generally identical to that used in adults. However, toddlers and infants require smaller endoscopes that have smaller working channels ${ }^{12}$. In adult gastroscopy, both physicians and surgeons carry out these procedures but there is paucity of pediatric endoscopist in Nigeria and other developing countries compared to the western world ${ }^{7-9}$.

It must be noted that administration of anesthesia in pediatric gastroscopy could be quite challenging, hence the on-going debate on the best form of anesthesia to use ${ }^{10}$. In the first patient,it was possible to establish that there was no foreign body stuck to the throat even though the child was insistent about it. In the second case, the cause of the upper GI bleed was convincingly determined and this settled the gamut ofdifferential diagnosis entertained before the procedure by the Pediatricians, hence aiding appropriate treatment.

The cost implication of pediatric endoscopy appears to be higher compared to gastroscopy in adults given the fact that an anesthetist is often required to administer anesthesia at an extra cost. Also, special equipment may also be required. This is even worse when such services are being offered in the private sector where there is no government subsidy,thus making the cost implications of accessing the service higher. It is important to provide pediatric endoscopy facilities in our public health institutions. Also, the dearth of pediatric endoscopist especially in developing countries needs urgent attention. There is need for training of personnel in pediatric endoscopy as well as create awareness in this emerging fieldin Nigeria as well as other developing countries.

\section{Conclusion}

Pediatric gastroscopy is an emerging field in Nigeria. Efforts should be made to make this service readily available, accessible and affordable in many centres in Nigeria as well as in other developing countries. There is need to train pediatric endoscopist as well as address the anesthetic challenges associated with it.

\section{References}

[1]. EABadoe,JFKTandoh,BNBaako. Stomach and Duodenum. In : EABadoe, EQArchampong,JTda-Rocha-Afodu (eds). Principles and Practice of Surgery -Including Pathology in the Tropics, 3 ( Accra: Assemblies of God Literature Centre Ltd. 2000) 588-89.

[2]. Neil J. McC. Mortensen. Stomach and Duodenum. In RCGRussel,NSWilliams,CJKBulstrode(eds). Bailey and Love's Short Practice of Surgery, 23(London: Arnold 2000) 906.

[3]. B LBass,D J Turner. Acute gastrointestinal hemorrhage. In MCourtney, R Beauchamp,BEvers,KMattox(eds). Sabiston Textbook of Surgery, 17(Elsevier Saunders 2004)1247-48.

[4]. DO Irabor. Surgical gastrointestinal endoscopy in Ibadan,Nigeria. Nigerian Journal of Surgical Research,2006, 8(3-4) ,161-162

[5]. A OMalu, GMSobala. Prevalence of gastric and duodenal ulcers at endoscopy in Nigerian and British patients. Afr J med Sci. 1995,24 (3),239-41.

[6]. SGJimenez, AGCatto-Smith. Impact of day-casegastroscopy on children and their families. J Gastrenterol Hepatol. 2008,23(3), 37984. 
[7]. S Amini-Ranjbar,Mohammad-Hossein Torabinejad. Diagnostic Endoscopy of Two Months to 15 years of Age. American Journal of Applied Sciences,2009, 6(10),1812-1814

[8]. RKingston, GByrnes,D O’Ceallaigh. Diagnostic yield of gastroscopy in a general surgical unit. Ir J med sci.1999,168, 268-70.

[9]. L-G Maite, J Brimacombe, D-R Gonzalo.Anesthesia for pediatric gastroscopy: a study comparing the proseal laryngeal airway with nasal cannulae. Paediatric Anaethesia, 2006, 16(10),1032-1035.

[10]. S C Nwokediuko, OObienu . World J GastrointestEndosc 2012,4(6), 260-256

[11]. R H. Squires, R B. Collett. Indications for Pediatric Gastrointestinal Endoscopy:A Medical Position Statement of the NorthAmerican Society for Pediatric Gastroenterology and Nutrition.Journal of Pediatric Gastroenterology and Nutrition , $1996,23,107-110$. 